\title{
Luminescence investigation of the $\mathrm{Sm}(\mathrm{III})-\beta$-diketonates with sulfoxides, phosphine oxides and amides ligands
}

\author{
H.F. Brito ${ }^{a}, *$ O.L. Malta ${ }^{b}$, M.C.F.C. Felinto ${ }^{c}$, E.E.S. Teotonio ${ }^{a}$, J.F.S. Menezes ${ }^{a}$, C.F.B. Silva ${ }^{a}$, \\ C.S. Tomiyama ${ }^{c}$, C.A.A. Carvalho ${ }^{\mathrm{d}}$ \\ ${ }^{a}$ Departamento de Química Fundamental, Instituto de Química da Universidade de São Paulo, 05508-900 São Paulo, SP, Brazil \\ ${ }^{\mathrm{b}}$ Departamento de Química Fundamental da UFPE-CCEN, Cidade Universitária, Recife, PE 50670-901, Brazil \\ ${ }^{\circ}$ Instituto de Pesquisas Energéticas e Nucleares Travessa, $R$ 400, Cidade Universitária, São Paulo, SP, CEP 05508-970, Brazil \\ ${ }^{\mathrm{d}}$ Departamento de Química da Universidade Federal de Ouro Preto, Ouro Preto, MG, Brazil
}

\begin{abstract}
In this paper we report on a photoluminescent investigation of complexes involving $\mathrm{Sm}^{3+}$ - $\beta$-diketonates with sulfoxides, phosphine oxides and amides ligands. In the synthesis of the coordination compounds we used samarium tris(thenoyltrifluoroacetonate) dihydrated precursor with the following ligands (L): DBSO and PTSO sulfoxides; TPPO phosphine oxide and (PHA) $N$-phenylacetamide. They have shown high orange luminescence characteristic of the $\mathrm{Sm}^{3+}$ ion. The emission spectra of the $\mathrm{Sm}^{3+}$-complexes present narrow bands arising from the ${ }^{4} \mathrm{G}_{5 / 2} \rightarrow{ }^{6} \mathrm{H}_{J}(J=5 / 2,7 / 2,9 / 2,11 / 2)$ transitions with the hypersensitive ${ }^{4} \mathrm{G}_{5 / 2} \rightarrow{ }^{6} \mathrm{H}_{9 / 2}$ transition as a prominent group. It is observed an efficient intramolecular energy transfer from the triplet state (T) of the ligands to the emitting ${ }^{4} \mathrm{G}_{5 / 2}$ state of the $\mathrm{Sm}^{3+}$ ion. The experimental intensity parameters $\left(\eta_{\mathrm{Sm}}\right.$ and $\left.\eta_{\mathrm{Eu}}\right)$ for the Sm and Eu complexes have been determined and compared. The lifetimes $(\tau)$ of the emitting level ${ }^{4} \mathrm{G}_{5 / 2}$ of the Sm-complexes are approximately 10 times higher than in the precursor compound $\left[\mathrm{Sm}(\mathrm{TTA})_{3} \cdot\left(\mathrm{H}_{2} \mathrm{O}\right)_{2}\right]$ indicating that radiative processes are operative in all the compounds due to the absence of multiphonon relaxation by coupling with the $\mathrm{OH}$ oscillators.
\end{abstract}

(C) 2002 Elsevier Science B.V. All rights reserved.

Keywords: Samarium; Luminescence; Thenoyltrifluoroacetonate; Sulfoxides and amides

\section{Introduction}

The application of compounds containing trivalent rare earth ions $\mathrm{RE}^{3+}$ is based mainly on their photoluminescence properties [1-6]. Luminescence investigation of $\mathrm{RE}^{3+}-\beta$-diketonate complexes has increased in the last decade due to the higher efficiency of energy transfer from diketonate ligands to rare earth ions, which can be explained by the high absorption coefficient of the $\beta$ diketonate ligands [3-6]. The interest in the photoluminescent study of these complexes is the development of efficient light conversion molecular devices (LCMD) [7]. Among the rare earth ions the most investigated are those compounds with trivalent europium and terbium ions, owing to their intrinsic electronic spectroscopic properties. However, the $\mathrm{Eu}^{3+}$ ion has attracted more attention than the $\mathrm{Tb}^{3+}$ ion probably due to the facilities in the interpreta-

\footnotetext{
*Corresponding author. Tel.: +55-11-3818-3708; fax: +55-11-3815 5579.

E-mail address: hefbrito@iq.usp.br (H.F. Brito).
}

tion of its energy level structure, considering that the former has a non-degenerate emitting level $\left({ }^{5} \mathrm{D}_{0}\right)$ [8], while the $\mathrm{Tb}^{3+}$ ion has an emitting state $\left({ }^{5} \mathrm{D}_{4}\right)$ multidegenerate. On the other hand, the compounds containing the $\mathrm{Sm}^{3+}$ ion have been less studied than those with $\mathrm{Eu}^{3+}$ and $\mathrm{Tb}^{3+}$ ions, taking into consideration that the trivalent samarium ion in general presents low luminescence intensity. The high luminescence of the rare earth tris(thenoyltrifluoroacetonate) complexes depends on the energy level structure of the ligands and metal ion. For instance, the ligand triplet states are at higher energies than the ${ }^{5} \mathrm{D}_{0}$ and ${ }^{4} \mathrm{G}_{5 / 2}$ emitting states of the $\mathrm{Eu}^{3+}$ and $\mathrm{Sm}^{3+}$ ions, respectively (Fig. 1). On the other hand, the $\left[\mathrm{Tb}(\mathrm{TTA})_{3} \cdot 2 \mathrm{~L}\right]$ complexes do not show any luminescences at all owing to the fact that the $\mathrm{T}$ states are at lower energy than the emitting ${ }^{5} \mathrm{D}_{4}$ level.

The $\mathrm{Sm}^{3+}$ ion has an odd-electron configuration $\left(4 \mathrm{f}^{5}\right)$ and, therefore, it is labeled as a Kramer ion due to its electronic states that are at least doubly degenerate for any crystal-field perturbation [9]. The maximum number of the Stark components for Kramer ions with ${ }^{2 \mathrm{~S}+1} \mathrm{~L}_{J}$ state is 


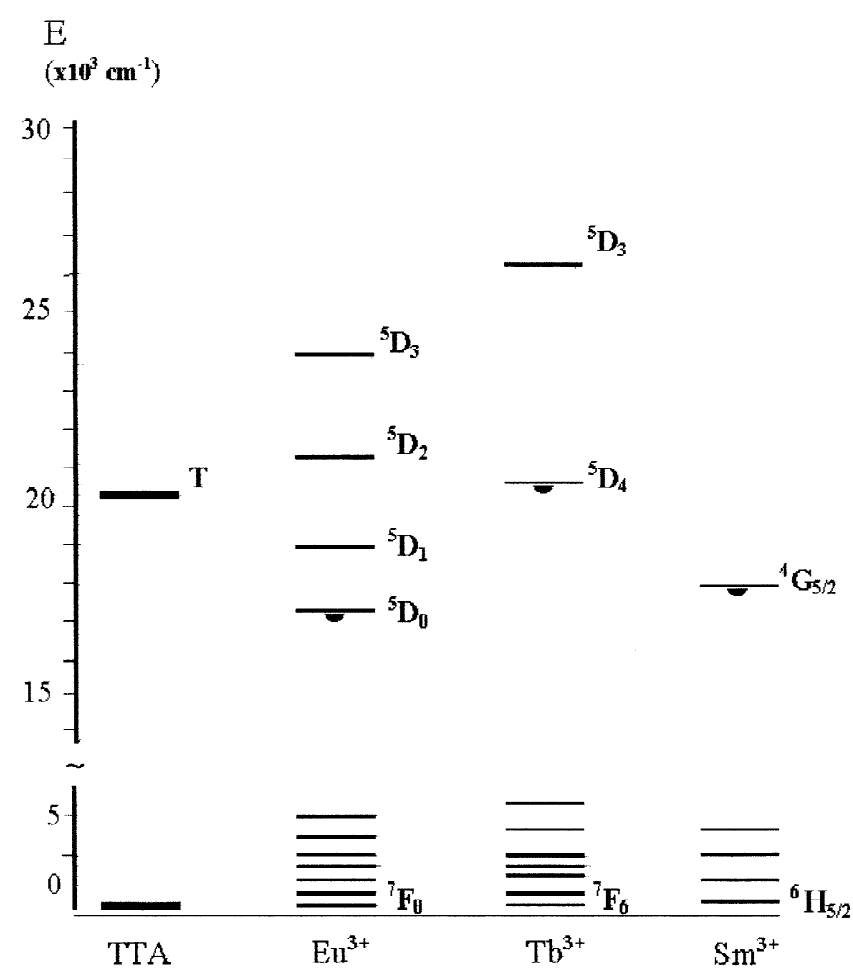

Fig. 1. Energy level diagram relating the triplet level (T) of the thenoyltrifluoroacetone counterion obtained from phosphorescence spectrum of $\left[\mathrm{Gd}(\mathrm{TTA})_{3} \cdot 2 \mathrm{H}_{2} \mathrm{O}\right]$ [15] and some energy levels of the trivalent rare earth ion $\left(\mathrm{Sm}^{3+}, \mathrm{Eu}^{3+}\right.$ and $\left.\mathrm{Tb}^{3+}\right)$.

$J+1 / 2$ for any symmetry lower than cubic [10]. The detailed analyses of the energy levels of $\mathrm{Sm}^{3+}$ in several hosts have been reported $[11,12]$.

In this work we present a study on the unusual luminescence intensity in the new $\mathrm{Sm}^{3+}-\beta$-diketonate compounds with sulfoxides, phosphine oxide and amide ligands. Our analysis is mainly dedicated to investigation about the influence of organic ligands in the energy transfer process to the metal ion. In addition, the Sm-ligand interaction will be studied via electronic spectroscopy based on the experimental intensity parameters $\eta_{\mathrm{Sm}}$, and the lifetime of the emitting state $\left({ }^{4} \mathrm{G}_{5 / 2}\right)$.

\section{Experimental details}

\subsection{Materials and procedures}

Thenoyltrifluoroacetonate (TTA), dibenzyl sulphoxide (DBSO), p-tolyl sulfoxide (PTSO), triphenylphosphine oxide (TPPO) were purchased from Aldrich, while the $N$-phenylacetamide (PHA) ligand was synthesized by the method describe in Ref. [13]. The infrared spectra were measured at room temperature in a Perkin-Elmer 1750FTIR spectrophotometer in the spectral range from 4000 to $400 \mathrm{~cm}^{-1}$. The $\mathrm{KBr}$ plates and nujol mull suspension techniques for the compounds and films of the free ligand were applied. The TG curves were recorded with a thermobalance TGA 50 under dynamic nitrogen atmosphere $(50 \mathrm{ml} / \mathrm{min})$ and heating rate of $10^{\circ} \mathrm{C} \mathrm{min}{ }^{-1}$ in the temperature range of 25 up to $900{ }^{\circ} \mathrm{C}$. The excitation and emission spectra were recorded in a spectrofluorometer SPEX-Fluorolog 2 with double grating 0.22 m SPEX 1680 monochromators, a 450-W Xenon lamp as excitation source and this apparatus was fully controlled by a DM3000F spectroscopic computer. The lifetime data of the $\left[\mathrm{Sm}(\mathrm{TTA})_{3} \cdot 2 \mathrm{~L}\right]$ complexes were obtained at room temperature, using the Phosphorimeter (SPEX 1934D) accessory coupled to the spectrofluorometer. The decay curves for the Sm-complexes at $298 \mathrm{~K}$ were recorded under excitation and emission around 377 and $648 \mathrm{~nm}$, respectively.

\subsection{Synthesis of the solid complexes}

The precursor compound $\left[\mathrm{Sm}(\mathrm{TTA})_{3} \cdot\left(\mathrm{H}_{2} \mathrm{O}\right)_{2}\right]$ was prepared by the method described by Charles and Ohlmann [14]. The only difference was that pentane was used instead of petroleum ether to remove the excess of chelating agent.

The trivalent samarium complexes were prepared by the method early described, for the compounds of europium with the sulfoxide ligands, by Malta et al. [15]. The trivalent samarium complexes were prepared by the dissolution of the crystals of $\left[\mathrm{Sm}(\mathrm{TTA})_{3} \cdot\left(\mathrm{H}_{2} \mathrm{O}\right)_{2}\right]$ and sulfoxide, phosphine oxide and amide ligands in ethanol. The solutions were added in the molar ratio 1:2 (precursor compound:ligand) and allowed to stand together until the formation of the pale-yellow precipitated. The solid products were recrystallized from acetone and dried under vacuum over anhydrous calcium chloride in the desiccator at room temperature.

\section{Results and discussion}

\subsection{Characterization}

The samarium content was determined by complexometric titration with EDTA in methanol. The carbon, hydrogen and nitrogen contents were estimated by microanalytical procedures. The $\mathrm{C}, \mathrm{H}, \mathrm{N}$ and $\mathrm{Sm}^{3+}$ percentage values calculated/found for the complexes with the respective ligands are: hydrated compound (C: 33.92/ 33.85; H: 1.90/1.92; $\left.\mathrm{Sm}^{3+}: 17.68 / 17.71\right)$, DBSO (C: 48.89/48.50; H: 3.39/3.15; $\left.\mathrm{Sm}^{3+}: 11.77 / 11.53\right)$, PTSO (C: 48.99/48.49; H: 3.16/3.19; $\mathrm{Sm}^{3+}: 11.91 / 11.53$ ), TPPO (C: 52.58/52.43; H: 3.09/3.39; $\mathrm{Sm}^{3+}: 10.97 /$ 10.39), and PHA (C: 44.25/43.45; H: 2.60/2.66; N: $2.58 /$ 2.71; $\left.\mathrm{Sm}^{3+}: 13.89 / 13.82\right)$.

The IR spectra of $\mathrm{Sm}^{3+}-\beta$-diketonate compounds with sulfoxides ligands show the displacement of the $\mathrm{S}=\mathrm{O}$ stretching from 1033 and $1039 \mathrm{~cm}^{-1}$ in the free DBSO and 
PTSO ligands to $\sim 1007$ and $1006 \mathrm{~cm}^{-1}$ in the compounds, respectively. The displacement of the $\nu \mathrm{C}=\mathrm{O}$ stretching from $\sim 1680 \mathrm{~cm}^{-1}$ in the free TTA ligand to $\sim 1607 \mathrm{~cm}^{-1}$ in the compounds suggesting that the coordination of the ligand to metal ion is occurring through the oxygen. In the case of the $\left[\mathrm{Sm}(\mathrm{TTA})_{3} \cdot(\mathrm{TPPO})_{2}\right]$ complex it is observed a displacement of the $\nu \mathrm{P}=\mathrm{O}$ stretching from $1191 \mathrm{~cm}^{-1}$ in the free TPPO ligand to $1172 \mathrm{~cm}^{-1}$ in complex, providing good evidence that the TPPO ligand is also coordinated through the oxygen atom. The IR spectrum of the $\left[\mathrm{Sm}(\mathrm{TTA})_{3} \cdot(\mathrm{PHA})_{2}\right]$ complex shows a shift to lower frequency $\left(1619 \mathrm{~cm}^{-1}\right)$ relative to the amide I band $(\nu \mathrm{C}=\mathrm{O})$ as compared with the free ligand $\left(1660 \mathrm{~cm}^{-1}\right)$, suggesting that coordination of PHA ligand occurs through the oxygen of the amide group. The IR results show the absence of bands around $3500 \mathrm{~cm}^{-1}$, which confirms that all the compounds are anhydrous.

The thermogravimetric curves of the complexes are shown in Fig. 2. The TG curve of the precursor [Sm(TTA $)_{3} \cdot\left(\mathrm{H}_{2} \mathrm{O}\right)_{2}$ ] presents a weight loss in temperature range $80-120^{\circ} \mathrm{C}$ that corresponds to release of water molecules. On the other hand, the TG curves of the complexes do not present any event in this region, showing the anhydrous character of these compounds. By comparing the thermal decomposition of the complexes it can be seen that the compound with the TPPO ligand presents the highest thermal stability.

\subsection{Photoluminescence study}

Fig. 3 shows the luminescence spectra of the $\left[\mathrm{Sm}(\mathrm{TTA})_{3} \cdot 2 \mathrm{~L}\right]$ complexes recorded in the range of 550

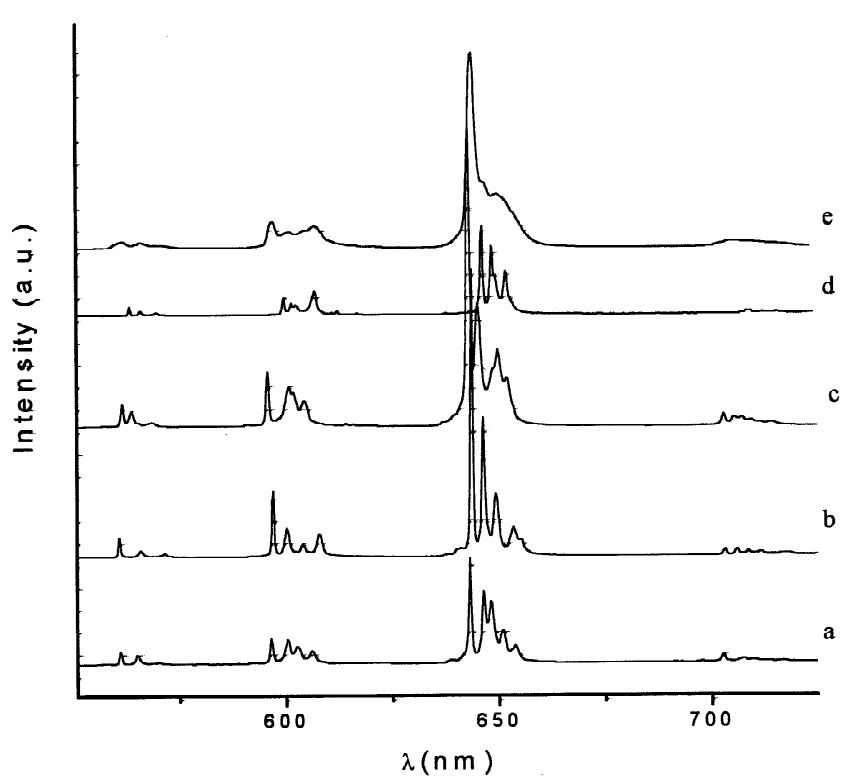

Fig. 3. Emission spectra of the $\left[\mathrm{Sm}(\mathrm{TTA})_{3} \cdot 2 \mathrm{~L}\right]$, at nitrogen liquid temperature, for the following ligands: (a) $\mathrm{H}_{2} \mathrm{O}$, (b) PHA, (c) TPPO, (d) DBSO, and (e) PTSO.

$725 \mathrm{~nm}$, at $77 \mathrm{~K}$. The emission spectra were also recorded at room temperature (omitting figures), which present similar profile as well as that at low temperature, but less resolved. The emission spectra of the complexes consist of narrow bands assigned to the ${ }^{4} \mathrm{G}_{5 / 2} \rightarrow{ }^{6} \mathrm{H}_{J}$ transitions (where $J=5 / 2,7 / 2,9 / 2$ and 11/2) of the $\mathrm{Sm}^{3+}$ ion. The electric dipole ${ }^{4} \mathrm{G}_{5 / 2} \rightarrow{ }^{6} \mathrm{H}_{9 / 2}$ transition presents the highest relative emission intensity around $648 \mathrm{~nm}$. The emission spectra (Fig. 3) show that the transitions split in a

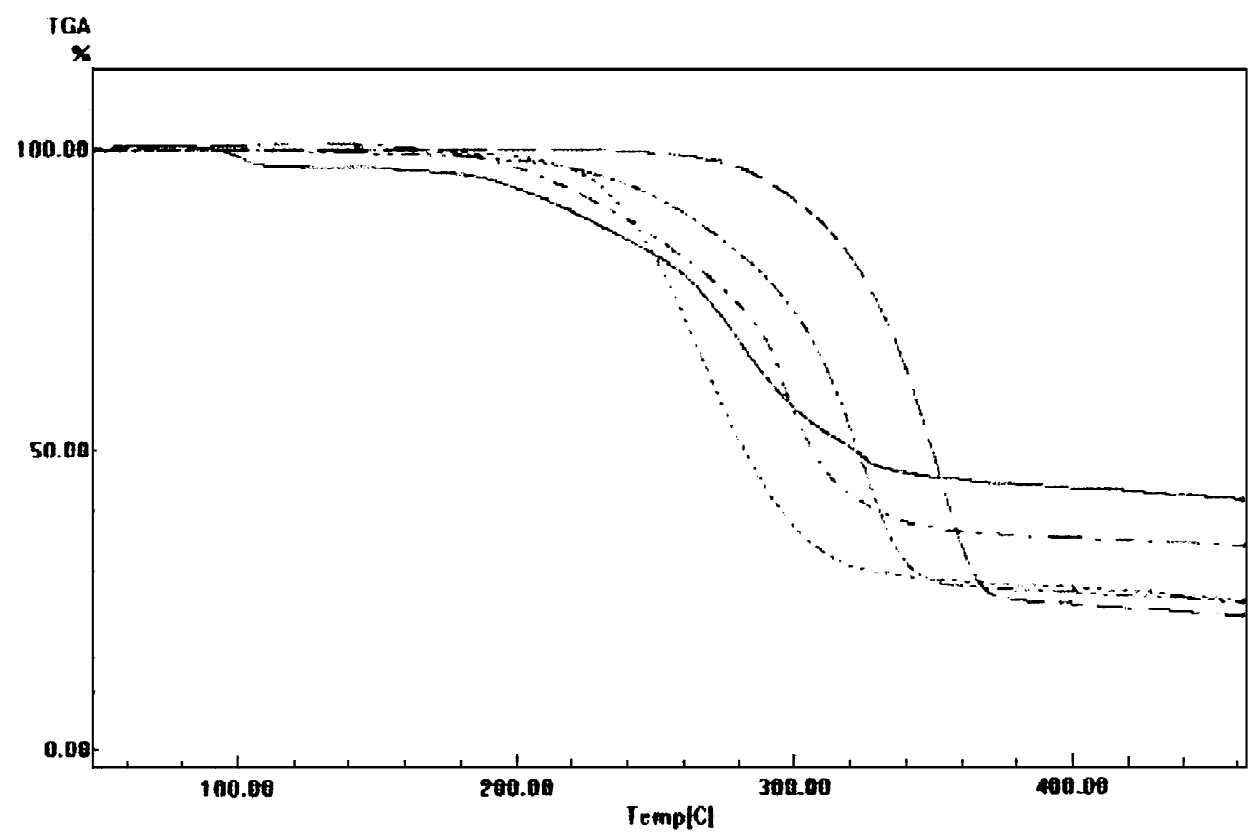

Fig. 2. TG curves of $\mathrm{Sm}^{3+}$ compounds containing the following ligands: $\mathrm{H}_{2} \mathrm{O}$ (solid line); PHA (dash-dot line); TPPO (dash line); DBSO (dot) and PTSO

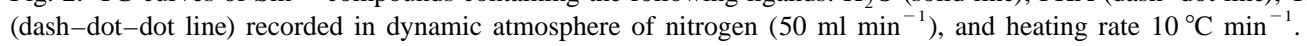


Table 1

Energies of the ${ }^{4} \mathrm{G}_{5 / 2} \rightarrow{ }^{6} \mathrm{H}_{5 / 2-11 / 2}$ manifolds $\left(\mathrm{cm}^{-1}\right)$ observed in the emission spectra of $\left[\mathrm{Sm}(\mathrm{TTA})_{3} \cdot 2 \mathrm{~L}\right]$, where $\mathrm{L}=\mathrm{H}_{2} \mathrm{O}$, TPPO, PHA, DBSO and PTSO

\begin{tabular}{|c|c|c|c|c|c|}
\hline Transitions & $\mathrm{H}_{2} \mathrm{O}$ & TPPO & PHA & DBSO & PTSO \\
\hline \multirow[t]{3}{*}{${ }^{4} \mathrm{G}_{5 / 2} \rightarrow{ }^{6} \mathrm{H}_{5 / 2}$} & 17825 & 17806 & 17832 & 17749 & 17806 \\
\hline & 17702 & 17737 & 17674 & 17665 & 17665 \\
\hline & 17544 & 17593 & 17495 & 17553 & 17525 \\
\hline \multirow[t]{7}{*}{${ }^{4} \mathrm{G}_{5 / 2} \rightarrow{ }^{6} \mathrm{H}_{7 / 2}$} & 16767 & 16784 & 16750 & 16675 & 16750 \\
\hline & 16658 & 16644 & 16661 & 16625 & 16642 \\
\hline & 16592 & 16617 & 16556 & 16600 & 16543 \\
\hline & 16502 & 16545 & 16453 & 16477 & 16485 \\
\hline & 15547 & 15552 & 15538 & 15475 & 15533 \\
\hline & 15475 & 15504 & 15470 & 15425 & 15468 \\
\hline & 15432 & 15418 & 15404 & 15404 & 15389 \\
\hline \multirow[t]{4}{*}{${ }^{4} \mathrm{G}_{5 / 2} \rightarrow{ }^{6} \mathrm{H}_{9 / 2}$} & 15361 & 15389 & 15305 & 15347 & 15361 \\
\hline & 15298 & 15337 & 15267 & 15312 & 15305 \\
\hline & 14337 & 14229 & 14221 & 14142 & 14190 \\
\hline & 14233 & 14180 & 14164 & 14118 & 14154 \\
\hline \multirow[t]{4}{*}{${ }^{4} \mathrm{G}_{5 / 2} \rightarrow{ }^{6} \mathrm{H}_{11 / 2}$} & 14160 & 14144 & 14112 & 14100 & 14094 \\
\hline & 14130 & 14096 & 14053 & 14047 & 14065 \\
\hline & 14094 & 14053 & 13951 & 14017 & 13999 \\
\hline & 13953 & 14002 & 13920 & 13982 & 13959 \\
\hline
\end{tabular}

maximum number of $(J+1 / 2)$-components (Table 1) indicating that the $\mathrm{Sm}^{3+}$ ion occupies a site with low symmetry.

The transition ${ }^{4} \mathrm{G}_{5 / 2} \rightarrow{ }^{6} \mathrm{H}_{5 / 2}$ (around $560 \mathrm{~nm}$ ) is taken as the reference due to its predominant magnetic dipole character $(\Delta J=0)$. On the other hand, the ${ }^{4} \mathrm{G}_{5 / 2} \rightarrow{ }^{6} \mathrm{H}_{9 / 2}$ transition is magnetic-dipole forbidden and electric-dipole allowed. From this transition we determined the $\eta_{\mathrm{Sm}}$ intensity parameter, which is the ratio between the intensities of the ${ }^{4} \mathrm{G}_{5 / 2} \rightarrow{ }^{6} \mathrm{H}_{9 / 2}$ and ${ }^{4} \mathrm{G}_{5 / 2} \rightarrow{ }^{6} \mathrm{H}_{5 / 2}$ transitions for the $\mathrm{Sm}^{3+}$-complexes [16].

The experimental intensity parameter $\eta_{\mathrm{Sm}}$ for the samarium complexes shows that the substitution of the two water molecules by the ligands increases the luminescence intensity in following order (Table 2): $\mathrm{H}_{2} \mathrm{O}<$ TPPO $<$ $\mathrm{PHA}<\mathrm{DBSO}<\mathrm{PTSO}$, illustrating the hypersensitive behavior of the ${ }^{4} \mathrm{G}_{5 / 2} \rightarrow{ }^{6} \mathrm{H}_{9 / 2}$ transition, indicating that the samarium ion is in a highly polarizable chemical environ-

Table 2

Experimental intensity parameters and lifetime $(\tau)$ of ${ }^{4} \mathrm{G}_{5 / 2}$ emitting level (ms) for the $\left[\mathrm{Sm}(\mathrm{TTA})_{3} \cdot 2 \mathrm{~L}\right]$ (where $\mathrm{L}=\mathrm{H}_{2} \mathrm{O}$, TPPO, PHA, DBSO and PTSO), at room temperature

\begin{tabular}{lrlrl}
\hline$\left[\mathrm{Sm}(\mathrm{TTA})_{3} \cdot 2 \mathrm{~L}\right]$ & \multicolumn{1}{c}{$\eta_{\mathrm{Sm}}{ }^{\mathrm{a}}$} & Barycenter & \multicolumn{1}{c}{$\eta_{\mathrm{Eu}}^{\mathrm{a}}$} & \multicolumn{1}{c}{$\tau$} \\
\hline $\mathrm{H}_{2} \mathrm{O}$ & 8.89 & 15497 & 8.90 & 0.0042 \\
DBSO & 12.54 & 15475 & 20.25 & 0.0677 \\
PTSO & 13.37 & 15492 & 20.85 & 0.1114 \\
TPPO & 11.70 & 15523 & 12.99 & 0.1298 \\
PHA & 12.15 & 15507 & 15.50 & 0.0370 \\
\hline
\end{tabular}

\footnotetext{
${ }^{a}$ Where the intensity parameters are ratio of intensities given by $\eta_{\mathrm{Sm}}={ }^{4} \mathrm{G}_{5 / 2} \rightarrow{ }^{6} \mathrm{H}_{9 / 2} /{ }^{4} \mathrm{G}_{5 / 2} \rightarrow{ }^{6} \mathrm{H}_{5 / 2}$ and $\eta_{\mathrm{Eu}}={ }^{5} \mathrm{D}_{0} \rightarrow{ }^{7} \mathrm{~F}_{2} /{ }^{5} \mathrm{D}_{0} \rightarrow{ }^{7} \mathrm{~F}_{1}$ for samarium and europium, respectively.
}

ment. Table 2 shows also the $\eta_{\text {Eu }}$ experimental intensity parameter for the $\left[\mathrm{Eu}(\mathrm{TTA})_{3} \cdot 2 \mathrm{~L}\right]$ complexes (where $\mathrm{L}$ is the same ligands coordinated to the Sm-complexes). The $\eta_{\mathrm{Eu}}$ parameter is given by the ratio between the area under curves of the hypersensitive ${ }^{5} \mathrm{D}_{0} \rightarrow{ }^{7} \mathrm{~F}_{2}$ transition allowed by electric-dipole and magnetic-dipole allowed ${ }^{5} \mathrm{D}_{0} \rightarrow{ }^{7} \mathrm{~F}_{1}$ transition, $\eta_{\mathrm{Eu}}={ }^{5} \mathrm{D}_{0} \rightarrow{ }^{7} \mathrm{~F}_{2} /{ }^{5} \mathrm{D}_{0} \rightarrow{ }^{7} \mathrm{~F}_{1}$. The $\eta_{\mathrm{Eu}}$ values show a behavior similar to that found for the Sm-complexes, corroborating with the electric-dipole character of the ${ }^{4} \mathrm{G}_{5 / 2} \rightarrow{ }^{6} \mathrm{H}_{9 / 2}$ transition from $\mathrm{H}_{2} \mathrm{O}$ to PTSO ligands. In addition, a higher polarizable chemical environment around the $\mathrm{RE}^{3+}$ ion is observed for the complexes ( $\mathrm{Sm}$ and $\mathrm{Eu}$ ) with sulfoxide ligands.

The energy of the triplet state (T) of the TTA ligand was obtained from the phosphorescence spectrum of the $\left[\mathrm{Gd}(\mathrm{TTA})_{3} \cdot\left(\mathrm{H}_{2} \mathrm{O}\right)_{2}\right]$ complex recorded at $77 \mathrm{~K}$ under excitation at $337 \mathrm{~nm}$ in the spectral region from 400 to 700 $\mathrm{nm}$ (omitted figure). The triplet states were taken as the shortest wavelength from the phosphorescence bands due to $0-0$ transition with energy level positions around of $21280 \mathrm{~cm}^{-1}$ [15].

The luminescence decay curves of the ${ }^{4} \mathrm{G}_{5 / 2}$ emitting level of Sm-complexes were monitored in the ${ }^{4} \mathrm{G}_{5 / 2} \rightarrow{ }^{6} \mathrm{H}_{9 / 2}$ transition [9]. The decay curves for the $\left[\mathrm{Sm}(\mathrm{TTA})_{3} \cdot 2 \mathrm{~L}\right]$ (where $\mathrm{L}=\mathrm{H}_{2} \mathrm{O}, \mathrm{PHA}, \mathrm{PTSO}, \mathrm{DBSO}$ and TPPO), at room temperature, were found to be a single exponential, indicating the existence of only one site symmetry around the $\mathrm{Sm}^{3+}$ ion. When we compare the lifetimes (Table 2) of all complexes it is observed that the $\left[\mathrm{Sm}(\mathrm{TTA})_{3} \cdot\left(\mathrm{H}_{2} \mathrm{O}\right)_{2}\right]$ precursor $(\tau=0.0042 \mathrm{~ms})$ shows the smallest value, indicating that the water molecules play a role in the non-radiative processes in the $\mathrm{Sm}^{3+}$ complexes. It is also noted that the complex with the PHA ligand has a smaller value of lifetime than those containing sulfoxide and phosphine oxide ligands. This is probably due to the presence of $\mathrm{N}-\mathrm{H}$ vibrations in the amide ligand that contribute to non-radiative deactivation of the ${ }^{4} \mathrm{G}_{5 / 2}$ emitting state of the $\mathrm{Sm}^{3+}$ ion [17].

\section{Conclusion}

The new $\left[\mathrm{Sm}(\mathrm{TTA})_{3} \cdot 2 \mathrm{~L}\right]$ complexes $\left(\mathrm{L}=\mathrm{H}_{2} \mathrm{O}\right.$, TPPO, PHA, DBSO and PTSO) show strong orange luminescence when excited by ultraviolet radiation. The IR data show a shift of the stretching $\nu \mathrm{X}=\mathrm{O}$ (where $\mathrm{X}=\mathrm{S}, \mathrm{P}$ and $\mathrm{C}$ ) to smaller frequencies in the $\mathrm{Sm}^{3+}$-complexes as compared with the free ligands, indicating that the coordination of the ligands to $\mathrm{Sm}^{3+}$ ion occur through the oxygen. The TG curves of the complexes do not show any event in the region up to $150{ }^{\circ} \mathrm{C}$, indicating that the compounds are anhydrous. The emission spectra of the samarium complexes present bands corresponding to the ${ }^{4} \mathrm{G}_{5 / 2} \rightarrow{ }^{6} \mathrm{H}_{J}$ transitions, where $J=5 / 2,7 / 2,9 / 2$ and $11 / 2$, with the highest intensity band being the hypersensitive 
${ }^{4} \mathrm{G}_{5 / 2} \rightarrow{ }^{6} \mathrm{H}_{9 / 2}$ transition. The Sm-complexes present lifetimes higher than the hydrated precursor, indicating the efficient luminescence quenching due to $\mathrm{OH}$ oscillators in the inner coordination sphere of $\mathrm{Sm}^{3+}$ ion in hydrated compound. The small value of the lifetime in the complex with the PHA ligand is probably due to $\mathrm{N}-\mathrm{H}$ vibrations that can act as a channel of deactivation of the ${ }^{4} \mathrm{G}_{5 / 2}$ emitting level. The experimental intensity parameters $\left(\eta_{\mathrm{Sm}}\right.$ and $\eta_{\mathrm{Eu}}$ ) presented the same ligand order: $\mathrm{H}_{2} \mathrm{O}<\mathrm{TPPO}<$ $\mathrm{PHA}<\mathrm{DBSO}<\mathrm{PTSO}$, showing the higher hypersensitive character of the transition ${ }^{4} \mathrm{G}_{5 / 2} \rightarrow{ }^{6} \mathrm{H}_{9 / 2}$ in the complex with the PTSO ligand. Based on these photoluminescence data we suggest that the $\mathrm{Sm}^{3+}-\beta$-diketonate complexes are promising candidates as efficient light-converting device molecular (LCDM) similar to the respective $\mathrm{Eu}^{3+}-\beta$-diketonate complexes.

\section{Acknowledgements}

The authors are grateful to the Fundação de Amparo à Pesquisa do Estado de São Paulo (FAPESP), Conselho Nacional de Desenvolvimento Científico e Tecnológico (CNPq) and Pró-Reitoria de Pesquisa da Universidade de São Paulo for financial support. We are grateful to A.A.S. Araújo and D.F. Parra for the help with the manuscript and fruitful discussions.

\section{References}

[1] G. Blasse, B.C. Grabmaier, in: Luminescence Materials, Springer, Heidelberg, 1994.
[2] J.-C.G. Bünzli, G.R. Choppin, in: Lanthanide Probes in Life, Chemical and Earth Sciences: Theory and Practice, Elsevier, Amsterdam, 1989, Chapter 7.

[3] G.F. de Sá, O.L. Malta, C.M. Donegá, A.M. Simas, R.L. Longo, P.A. Santa-Cruz, E.F. da Silva Jr., Coord. Chem. Rev. 196 (2000) 165.

[4] O.L. Malta, H.F. Brito, J.F.S. Menezes, F.R.G. Silva, C.M. Donegá, S. Alves Jr., Chem. Phys. Lett. 282 (1998) 233.

[5] I. Hemmilä, T. Stahlberg, P. Mottran, in: Bioanalytical Applications of Labeling Technologies Immunoassays, Wallac, Turku, 1994.

[6] A.O. Yoshimasa, in: Hiap L. Ong (Ed.), Electroluminescent Display, Vol. 1, World Scientific, Singapore, 1995.

[7] N. Sabbatini, M. Guardigli, J.M. Lehn, Coord. Chem. Rev. 123 (1993) 201.

[8] H.F. Brito, V.R.L. Constantino, M.A. Bizeto, J. Alloys Comp. 311 (2) (2000) 159.

[9] P.S. May, D.H. Metcalf, F.S. Richardson, R.C. Carter, C.E. Miller, J. Luminesc. 51 (1992) 249.

[10] L. Beaury, J. Hölsä, J. Korventausta, J.C. Krupa, R.J. Lamminmäki, P. Porcher, H. Rahiala P., E. Säilynoja, Acta Phys. Polonica A 90 (1997) 1203.

[11] J.B. Gruber, B. Zandi, M.F. Reid, Phys. Rev. 60 (1999) 15643.

[12] S.B. Stevens, C.A. Morrison, M.D. Seltezer, M.E. Hills, J.B. Gruber, J. Appl. Phys. 70 (1991) 948.

[13] J. Anand, N.C. Singha, D.N. Sathyanarayana, J. Mol. Struct. 412 (1997) 221.

[14] R.G. Charles, R.C. Ohlmann, J. Inorg. Nucl. Chem. 27 (1965) 255.

[15] O.L. Malta, H.F. Brito, J.F.S. Menezes, F.R.G. Silva, S. Alves Jr., F.S. Farias Jr., A.V.M. de Andrade, J. Luminesc. 75 (1997) 255.

[16] W.D. Horrocks Jr., M. Albin, Prog. Inorg. Chem. 31 (1983) 1.

[17] S. Salama, F.S. Richardson, J. Chem. Phys. 84 (1980) 512. 